\title{
Living in a changing Chinese urban landscape: The Dalian case study
}

Dalian is the second-most important city in the southern part of Liaoning Province in northeast China. The city can trace its history back to the Qingniwa settlement. This settlement was occupied from 1858 until 1950 in succession by the British, Japanese and Russian Empires, with each imposing its own building styles on the city. However, from 1950, when the city was finally returned to China by the Russians, who had captured it from the Japanese during the Second World War, most of the imperial buildings and sites were lost to redevelopment within the city. The most dramatic changes have taken place since 1984, when the city was declared a Special Economic Zone, and particularly during the 1990 s, when Bo Xilai became the mayor and introduced parks, extensive motorways and many traffic circles. At present, having lost most of its traditional built environment, Dalian is a modern city marked by dramatic housing developments and dominated by multi-family high-rise buildings to accommodate its population of 5.72 million. In 2011, a survey was conducted among 400 inhabitants of the city to ascertain their perceptions concerning life in Dalian and the Dalian Development Zone, their living conditions and their level of satisfaction with their housing. From the survey, it was clear that the majority of the interviewees were uncertain about the variables concerning the structural quality of their housing units and the nature, quality and accessibility of the services provided. However, most of them indicated that public transport, open spaces, parks and recreational facilities were within easy reach of their housing units.

Key words: housing, services, quality of life, Dalian, China 


\section{Introduction}

"Concern over the quality of modern life is a characteristic of contemporary society. Social commentary of all kinds is replete with references to the quality of modern living" ( $\mathrm{Pa}-$ cione, 2003: 19). This paper makes observations about life, living conditions and housing in a rapidly changing Chinese urban landscape and is based on the constantly evolving city of Dalian, the second-most important urban area in Liaoning Province in northeast China. From the outset, it must be stated that no attempt was made to evaluate the quality of life (QOL), as such, within the city, although some of the variables that have been used by many scholars (e.g., Pacione, 1990; Dunn, 2002; Smith et al., 2003; Diaz-Serrano, 2009; Baiden et al., 2011) in their quality-of-life studies were used to evaluate life and living conditions within the city. To set the scene for this case study, we present a concise overview of the QOL theory and housing-satisfaction theory.

QOL should be seen against the backdrop of a person's perceptions of his or her position in life against the milieu of the individual's culture and the prevailing societal value system of the population in the region where he or she resides. The norms, goals, hopes and fears of that individual should also be taken into consideration (Pacione, 2003; Zhou et al., 2011). In essence, the relationship between humans and their environment is the quintessential geographical question that lies at the core of social geography. In an urban context, this can be explained as the concern that an urbanite would have for his or her urban surroundings (milieu) as experienced personally in a positive or negative way (Pacione, 2003). However, interpretations of the concept of QOL differ a good deal because this concept is used in a wide range of applications. In general, though, it is intended to refer to either conditions of the environment in which people live (the natural environment and housing) and/or attributes of the population themselves (Pacione, 2003).

According to Burç Ülengin et al. (2001), many scholars from a variety of disciplines have studied QOL since the 1930s because it was regarded as a tool for the effective allocation of scarce resources. The results of these studies were seen as a means to be employed in the distribution of scarce resources in line with the needs and priorities of the respective populations. Therefore, QOL can be divided into certain domains, such as overall QOL, physical health, psychological health, social relationships and the environment (Wang et al., 2010).

Central to interest in QOL research is the link between individuals and their everyday environments, but also the opportunity to improve or enhance this so-called "everyday" life (Pacione, 2003; Higgins \& Campanera, 2011). Accord- ing to Wim Naudé et al. (2009), most recent endeavours to measure QOL involve the compilation of a list of indices that includes a wide range of variables. However, all of these indices have their limitations in that they are unable to capture the multidimensional nature of QOL and the environmental aspects of the phenomenon. Further problems encountered with QOL studies and their contradictory findings can be attributed to differences in the choice of sets of variables, how the variables were weighted, the approaches and methodology used and, finally, the interviewees chosen and the homogeneity of the geographical study area (Ülengin et al., 2001). Another problem is human subjectivity. According to Margaret Westaway (2006), some individuals rate their QOL as very good despite living under very difficult conditions and vice versa. However, researchers such as Zahava Gabriel and Ann Bowling (2004), Bärbel Tress and Gunther Tress (2001) and Charles Perrings (1998) have established that there is generally a positive correlation between a superior QOL and a satisfactory physical location or surroundings.

In considering how to best determine an individual's subjective wellbeing or happiness, Luis Diaz-Serrano (2009) states that various domains such as work conditions, the financial situation, housing, health and the environment could have an impact. The satisfaction level within each of these domains depends not only on the individual's actual circumstances but also on the interviewee's personal ambitions and desires in each of these domains (Easterlin, 2006). However, one of these domains - housing and residential satisfaction - is universally seen and acknowledged by scholars as one of the most important elements that individuals regard as representative of a good overall QOL (Dunn, 2002; Smith et al., 2003; Diaz-Serrano, 2009; Baiden et al, 2011). Valerie Møller (2001) has even gone so far as to say that housing is the most important predictor of life satisfaction. Nevertheless, residential satisfaction is one of the most elusive of these references and the perceived QOL within neighbourhoods is also one of the most intangible measures to assess (Pacione, 2003).

Individuals' housing requirements are fulfilled and influenced by a range of residential, neighbourhood and personal attributes (Galster \& Hesser, 1981). According to Gabriel and Bowling (2004) and Anneli Kährik et al. (2012), when individuals are living in a neighbourhood that is perceived to give pleasure and a feeling of safety and that provides access to facilities such as municipal services and workplaces and is also in close proximity to friends and family, this urban landscape will seem to enhance their QOL, especially in their later years. In addition, a positive attachment to a place positively affects the cognitive and behavioural bonds that people develop over time with their social and physical environment (Bonaiuto et al. 2003). Consequently, the chances are that this residential environment, or the quality of the landscape, will greatly impact the 
QOL and residential satisfaction of the local population (Temelová \& Dvořákoná, 2012).

Urban areas constitute part of the landscape in which we live and, by appreciating human perceptions of these landscapes, we are able to understand the interaction between humans and their environment. Human activities and actions affect a landscape, but in turn, the way in which this landscape manifests itself also has an impact on humans (Tress \& Tress, 2001; see also Moolla et al., 2011). Numerous scholars have dealt with the connection between components of the landscape and human perception. According to Sang-Woo Lee et al. (2008), these studies have been conducted according to specific methods and their subsequent classifications have been clearly differentiated into positive or negative, and have, at the same time, reflected on this interface.

Past studies have consistently shown that humans prefer the natural environment over the constructed milieu of urban areas, and it is for this reason that people are more appreciative of parks and open areas and the presence of elements such as trees within an urban landscape. Such conditions and perceptions will lead to higher levels of neighbourhood satisfaction (Lee et al., 2008). Andrew McCulloch (2012) maintains that the choice of areas in which humans prefer to live depends on what they perceive as a desirable environment. Trends within the British population indicate that they find urban areas to be unattractive surroundings, as opposed to the perceptions of many other European countries' urban inhabitants. Research findings in Britain revealed that high-density housing has a negative impact on housing satisfaction and that relatively well-off families with children tend to move out of the big city in favour of areas with lower population and housing densities, such as those on the urban periphery or free-standing towns and seaside retirement areas.

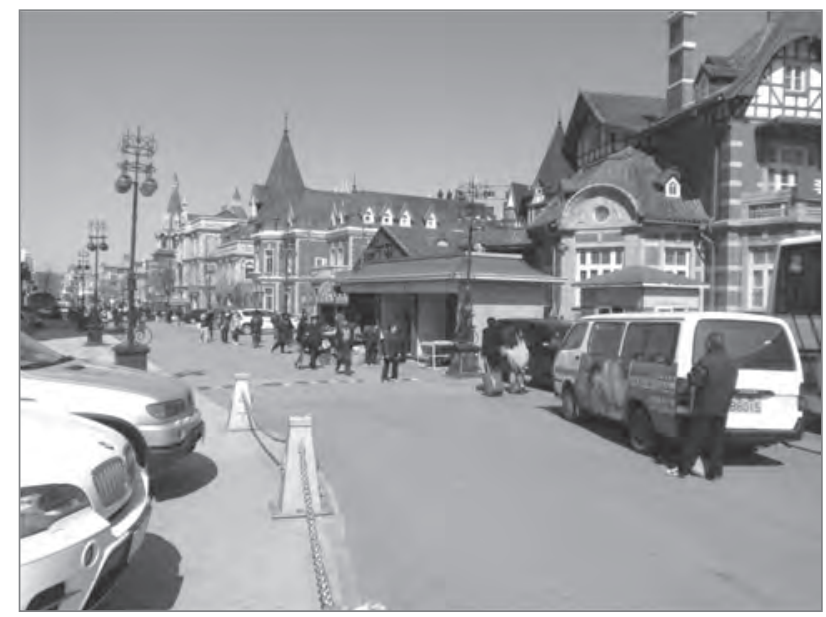

Figure 1: Russian Street in downtown Dalian (photo: Nico Kotze).
This case study is rooted in geography and, because its focus is on the interviewees' perceptions of life and their living environment in the changing urban environment of Dalian, a more detailed discussion of QOL indices is beyond the scope of this paper. The aims of the paper are to determine:

- The socioeconomic characteristics of Dalian's inhabitants;

- The housing attributes and the interviewees' levels of satisfaction with their housing units;

- Finally, the interviewees' perceptions of living conditions in Dalian, as demonstrated in how they perceive their surroundings and their proximity to services.

This paper is divided into five sections. The first section provides a brief historical overview of urban development in Dalian. The second section is an overview of the data and methodology used. The third section looks at the interviewees' socioeconomic background, and the fourth and fifth sections include the interviewees' perceptions of housing attributes and services and the characteristics of their respective environments or surroundings.

\section{Brief historical overview of the development of modern Dalian}

Dalian is a major city and harbour, as well as the second-largest city in Liaoning Province in northeast China. The city had a long history as a port used by foreign powers and dates back to the 1880s, when the Qing government constructed a loading bridge at a small town known as Qingniwa, and also established mining camps and built fortifications on the northern coast of what is today central Dalian. This settlement was occupied in 1858 by the British, who established a naval base known as Port Arthur (Mu et al., 2012; Travel China Guide, 2012). The area was returned to the Chinese in the 1880s but occupied by Japan in 1895 during the first Sino-Japanese War. After a failed attempt by the Japanese, the Russian Empire succeeded in leasing the peninsula from the Qing Dynasty in 1898, and founded the city named Dalny. This city was linked to the Trans-Siberian Railway line and became Russia's most important port in Asia. Dalny, as well as the neighbouring Port Arthur, was further developed and heavily fortified by the Russians in the period prior to 1904, but was lost to the Japanese during the Russo-Japanese War of 1905 (Mu et al., 2012; China Tour Online, 2012).

After the Russo-Japanese War, Japan set up the Kwantung Leased Territory, which occupied roughly the southern half of present-day Dalian. In 1932, Manchukua was founded and the sovereignty of the territory moved from China to Manchukuo, with Japan remaining as the leasing authority. In 1937, the 
area that became the current Dalian was modernised by the Japanese and became two cities, Dairen (Dalian) in the north and Ryojun (Port Arthur or Lüshun) in the south. After the Second World War and the unconditional surrender of Japan in August 1945, Dairen passed to the USSR, the liberator and governor of the city until 1950. During this period, the USSR and China cooperated in its further development, especially in establishing an industrial infrastructure and constructing its harbour facilities. The city remained a free port that was rented by the Soviet government (China Tour Online, 2012).

In 1950, the USSR returned the city to the Chinese communist government and on 1 December 1950 it was united with Lüshun (formerly Port Arthur). In 1955, the Soviet troops withdrew from the city and, with their departure, it was converted into a major shipbuilding hub and subsequently named Dalian in 1981. In 1984, the Chinese government designated the city a Special Economic Zone in order to attract foreign investment and companies to the area. At that time, Dalian was China’s largest foreign trade port. In the 1990s, the city benefited from the influence of Bo Xilai, who was both the mayor of the city and a provincial party official. Among other things, Xilai developed large parks and extensive motorways and many traffic circles (Travel China Guide, 2012). In 2006, the estimated population of the city was 5.72 million, making it the 13th-largest city in China (Geng et al, 2009). Although most of the traditional architecture was lost, Xilai was responsible for the preservation of Dalian's attractive Japanese and Russian architectural heritage around Zhongshan Square (see Figure 1).

The city as it is today serves as a regional financial base with a large industrial system, plays an important role in international shipping and is the key hub of land and sea communications in northeast Asia (Geng et al., 2009). Steps that have been taken in the short and long term to deal with its development include plant relocations, equipment renovations, the use of foreign environmental technology and market incentives to induce compliance with policies (Shin, 2004). Furthermore, pollution-reduction policies have also been put in place.

Today, Dalian is a modern city consisting of a high percentage of multi-family high-rise residential buildings, resulting in the loss most of its traditional built environment. However, there are other concerns that have arisen from its development, namely the threat to the available water resources, overuse of groundwater and deterioration in water quality (Geng et al., 2009). These changes to the built and the natural environment raise the following question: How do the inhabitants of this ever-changing landscape cope with daily life?

\section{Data collection and analyses}

The sample size for this case study was 400 (the sample units were households). Two hundred questionnaires were administered in downtown Dalian and the Dalian Development Zone, respectively. The initial idea was to compare the results from the two areas, but this was thrown out on account of the insignificant difference between these results. However, because no re-test was performed to check the reliability of this case study's findings, it does raise the question of the validity of the findings, in principle. In its favour, the questions posed in the survey were simple and the interviewees had no problems in answering them. Moreover, a fieldworker was always available to assist them.

A structured questionnaire with a consent form was used to gather information on demographic variables (gender, age, number of people in a household and employment status), housing information (ownership, period spent in the housing unit, number of bedrooms, the presence of a lift in the building and satisfaction levels concerning the bathroom, kitchen and the housing unit as a whole). These variables were each scored 1 for "dissatisfied", 2 for "uncertain" and 3 for "satisfied". Finally, the interviewees' perceptions about their neighbourhoods and the services that could contribute towards QOL (proximity to public transport, parks, open spaces, schools and shops) were targeted. Again a three-point scale was used, ranging from 1 for "close proximity" to 3 for "remote". The questionnaire was originally in English and the answers appeared appropriate at first glance, which suggested good face validity. However, it was then translated into Mandarin and it appears that some of the meanings were distorted in the final version, such that a few questions were disregarded.

Two of the biggest problems associated with this study were the language barrier, as well as access to the data and, for that matter, willing interviewees. Initially, no problems cropped up in the pilot study. However, when the data were processed, it was found that some details had been lost in translation and a number of questions had to be disregarded in the final study. Of the 400 completed questionnaires, a total of 12 had to be disregarded because of incomplete data sets, bringing the sample size down to 388 . To overcome the second constraint namely, access to interviewees - it was decided to contact organisations within the two areas in the city for permission to conduct the study among their employees. Eighteen companies gave permission for the questionnaires to be administered among their workers on a voluntary basis. A wide range of firms gave permission for their workers to be included in this study on a voluntary basis. The firms ranged from an American fast-food franchise to construction and computer-software companies. Employees of Dalian Nationalities University were 
also involved. This at least partly ensured that people from all walks of life and socioeconomic status levels were included in the case study.

The problems encountered, as well as the contradictory results obtained in QOL studies according to Ülengin et al. (2001), can be attributed to variations in the sets of variables chosen, the weights attached to these variables, the approaches and the methodology employed, and also the homogeneity of the interviewees and the geographical area. For this reason, only descriptive analyses of some of the variables that could have an impact on life and living conditions in Dalian were investigated.

\section{Household socioeconomic attributes}

This section involved an examination of the socioeconomic characteristics of the interviewees that were included in this case study. From the study, it was clear that a strongly paternalistic system is still in place within the city of Dalian, with $73 \%$ of the interviewees indicating that the head of the household was male (see Table 1). However, a scrutiny of the individual questionnaires revealed that there are a number of single women living on their own in the city. The largest number of interviewees indicated that the head of the household fell into the age category 30 years and younger (37.9\%), with the 31-to-40 age group being the second-largestage category. These results could have been distorted by the method used to collect the data.

Looking at the number of people per household, the one-child family planning policy of the Chinese government is clearly noticeable, with almost $95 \%$ of the interviewees indicating that their particular households consisted of three or fewer people. Just over $30 \%$ of the interviewees indicated that they were living on their own (see Table 1). The largest percentage, $42.2 \%$, revealed that two people were sharing the housing unit, whereas $22.9 \%$ of the interviewees indicated that there were three people in the unit. From the raw data in the questionnaires, it could be ascertained that they usually consisted of a married couple with a child. A small minority (4.2\%) indicated that four or more people were living together. In most cases this was a grandparent living with the household or else a group of young people sharing a company-owned apartment.

Again, as in the case of the age variable, the results for the head of household's employment status and qualifications could be a misrepresentation due to the data collection method used in the case study. Ninety-one percent indicated that the head of the household was permanently employed, whereas unemployed or retired household heads contributed only $4.3 \%$ and $4.7 \%$,
Table 1: Household socioeconomic attributes

\begin{tabular}{|c|c|}
\hline Variables & Percentage (\%) \\
\hline \multicolumn{2}{|c|}{ Gender of head of household } \\
\hline Male & 73.0 \\
\hline Female & 27.0 \\
\hline \multicolumn{2}{|l|}{ Age of head of household } \\
\hline$\leq 30$ years & 37.9 \\
\hline $31-40$ years & 36.4 \\
\hline $41-50$ years & 11.8 \\
\hline$>50$ years & 13.9 \\
\hline \multicolumn{2}{|c|}{ Number of people in housing unit } \\
\hline 1 & 28.3 \\
\hline 2 & 44.6 \\
\hline 3 & 22.9 \\
\hline$\geq 4$ & 4.2 \\
\hline \multicolumn{2}{|c|}{ Qualification of head of household } \\
\hline High school & 19.5 \\
\hline Tertiary qualification & 79.4 \\
\hline No answer & 1.1 \\
\hline \multicolumn{2}{|c|}{ Employment status of head of household } \\
\hline Permanently employed & 91 \\
\hline Unemployed & 4.3 \\
\hline Retired & 4.7 \\
\hline \multicolumn{2}{|c|}{ Number of income earners in household } \\
\hline One & 28.6 \\
\hline Two & 61.4 \\
\hline Three or more & 7.4 \\
\hline No answer & 2.6 \\
\hline
\end{tabular}

respectively, to the total (see Table 1). On the other hand, this category could also account for an elderly parent, an unmarried child or an unemployed spouse sharing an apartment. The majority of the interviewees $(61.4 \%)$ indicated that theirs was a two-income-earning household and only $28.6 \%$ indicated that they were members of a one-income-earning household. Concerning the qualifications, almost $80 \%$ indicated that the head of the household had a tertiary qualification, whereas 19.5\% had a high school qualification (see Table 1).

\section{Perceptions on housing in Dalian}

One of the most striking characteristics of Dalian's skyline since the 1990s is a reflection of the large number of multi-family high-rise residential buildings. These developments provide accommodation to the population in the form of oneto three-bedroom apartments ranging in size from $60 \mathrm{~m}^{2}$ and smaller for a one-bedroom apartment to units of $140 \mathrm{~m}^{2}$ or larger for a three-bedroom apartment. In 2012, an average $80 \mathrm{~m}^{2}$, newly built, two-bedroom apartment in the Dalian Development Zone could cost between RMB 600,000 and 800,000 (USD 94,000 and 125,000), depending on the type 
Table 2: Interviewees' housing units

\begin{tabular}{ll}
\hline Variables & Percentage (\%) \\
\hline Ownership & 70.3 \\
\hline Owner & 29.7 \\
\hline Tenant & \\
\hline Time in housing unit & 65.1 \\
\hline$\leq 5$ years & 21.7 \\
\hline $6-10$ years & 6.9 \\
\hline $11-15$ years & 3.2 \\
\hline $16-20$ years & 3.1 \\
\hline$>20$ years & 28.2 \\
\hline Number of bedrooms & 58.5 \\
\hline 1 bedroom & 13.3 \\
\hline 2 bedrooms & \\
\hline 3 bedrooms & 67.2 \\
\hline Lift in building & 32.8 \\
\hline Yes & \\
\hline No & 32.6 \\
\hline Satisfied with kitchen & 49.9 \\
\hline Yes & 17.5 \\
\hline Uncertain & 15.3 \\
\hline No & 60.9 \\
\hline Satisfied with bathroom & 23.8 \\
\hline Yes & \\
\hline Uncertain & \\
\hline Satisfied with the quality of the housing unit & \\
\hline Yes & \\
\hline Uncertain & \\
\hline
\end{tabular}

of development, whereas in downtown Dalian property prices could be up to $33 \%$ higher due to demand.

In the recent past, the cost of housing has increased dramatically and consistently, with the result that wealthier people have opted to buy a second property in the fear that their offspring might not be able to afford housing units at a later stage. Some of these second-home apartments are unoccupied, as can be observed by night, with a moderately large number of units without any sign of occupation (an observation the authors have made since 2010 that has been confirmed by Chinese colleagues).

In a study on the development of multi-family high-rise residential buildings in São Paulo by Sheila Walbe Ornstein et al. (2011), it was found that these housing developments have shown a decrease in the size of their individual three-bedroom units from $140 \mathrm{~m}^{2}$ in the 1950 s to only $85 \mathrm{~m}^{2}$ and smaller in the 2000s, although since the 1980s more attention has been given to communal living-space in order to ensure greater comfort in these units. To what extent this applies in Dalian is unclear but, according to some observers, the newly developed apartments are larger because of greater lifestyle demands by the Chinese population, which go hand-in-hand with an increase in the wealth of the country's population. Secondly, on looking at the floor plans of new apartment developments in Dalian, it is evident that much more attention is being given to design to optimise the flow of movement of the inhabitants in the apartments.

QOL studies indicate that home ownership intensifies people's perceptions of wellbeing or happiness (Dunn, 2002; Smith et al., 2003; Diaz-Serrano, 2009; Baiden et al., 2011; Møller, 2001). Furthermore, it was found in Hong Kong that housing prices do not necessarily respond to a change in environmental quality as the result of comprehensive redevelopment of older neighbourhoods (Yau, 2011). This investigation into housing attributes and the satisfaction levels of the interviewees with their housing units revealed that more than $70 \%$ own the housing unit they live in (see Table 2). In this sample the number of years that they have been living in the unit correlates with the age of the population, with $65.1 \%$ of the interviewees indicating that they have been living in the unit for 5 years or fewer, whereas only $3.1 \%$ have been living in the same apartment for more than 20 years.

The majority of interviewees (58.5\%) indicated that they were living in two-bedroom apartments. This could indicate that the present-day Chinese family consists of three people - in keeping with the government's one-child policy. Only 13.3\% indicated that their units consist of three bedrooms (see Table 2). More than $67 \%$ indicated that their apartment blocks had lifts, which would contribute towards a more comfortable way of life for people in the large number of multi-family high-rise residential buildings being constructed in the city.

Satisfaction levels were tested against the criterion of two rooms within the apartment that use water and electricity, namely the kitchen and the bathroom, and could be regarded as the

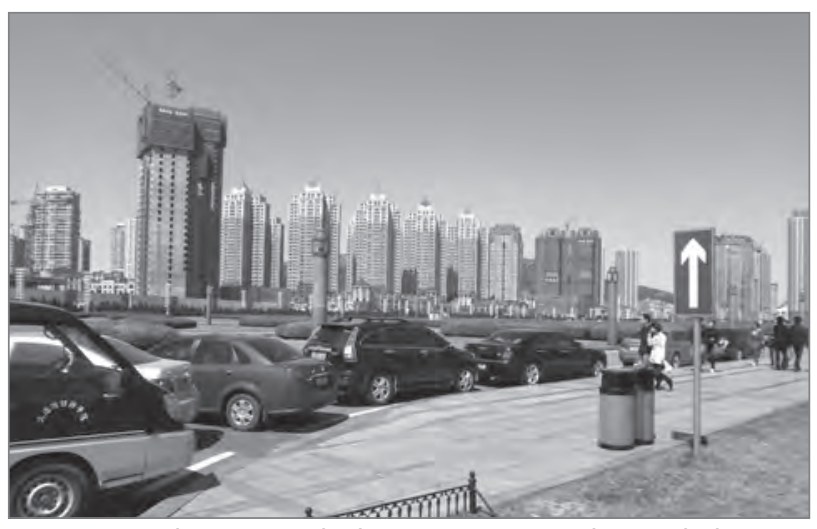

Figure 2: Xinghai Square, the largest square in Dalian, with the most expensive apartments (photo: Nico Kotze). 
Table 3: Interviewees' perceptions of services and the surrounding area

\begin{tabular}{ll}
\hline Variables & Percentage (\%) \\
\hline Proximity to parks & 61.7 \\
\hline Close & 38.3 \\
\hline Medium distance & 0 \\
\hline Far away & \\
\hline Proximity to open spaces & 75.4 \\
\hline Close & 24.6 \\
\hline Medium distance & 0 \\
\hline Far away & \\
\hline Proximity to public transport (busses) & 64.8 \\
\hline Close & 29.3 \\
\hline Medium distance & 5.9 \\
\hline Far away & \\
\hline Proximity to public transport (trains) & 6.3 \\
\hline Close & 33 \\
\hline Medium distance & 60.7 \\
\hline Far away & 26.8 \\
\hline Proximity to schools & 6.3 \\
\hline Close & 48.4 \\
\hline Medium distance & 45.8 \\
\hline Far away & 5.8 \\
\hline Proximity to medical facilities & \\
\hline Close & 27.9 \\
\hline Medium distance & \\
\hline Far away & \\
\hline Proximity to shops & \\
\hline Close & \\
\hline Medium distance & \\
\hline Par away & \\
\hline
\end{tabular}

areas possibly causing the most problems. In the case of both these rooms, as well as the total housing unit, the satisfaction levels were fairly low. The uncertain response category proved to be relatively high (almost $50 \%$ for the kitchen, more than $60 \%$ for the bathroom and $66 \%$ for the total apartment), most probably due to the civility of the Chinese population in not wishing to offend. However, dissatisfaction with the kitchen and the bathroom was reported in $17.5 \%$ and $23.8 \%$ of the cases respectively. From these figures it could be deduced that the interviewees were not satisfied with the apartments that they were occupying.

Finally, in Dalian, as in São Paulo (see Ornstein et al., 2011), a few of the new multi-family high-rise developments have started to offer other facilities such as swimming pools, fit- ness centres, playgrounds and green areas in communal areas, usually accommodated within the housing unit or at other localities. Such developments are still in their initial stages of development in Dalian. Only time will tell whether these communal spaces will remain as infrequently used on a daily basis by the residents of these establishments as was found in the case study in São Paulo.

\section{Perceptions on living in Dalian}

In this section, the perceptions of the interviewees concerning their living conditions were determined by establishing their perceptions of their surroundings and their proximity to the services offered. As stated earlier, universally humans prefer the natural environment over the constructed milieu of urban areas. Consequently, parks, open areas and elements such as trees are more appreciated (Lee et al., 2008). Dalian's location on a peninsula with moderate to steep hilly topography made close proximity to nature a reality during city planning. A journey along the many broad, multilane highways and freeways in and around downtown Dalian and the Dalian Development Zone makes this evident. In contrast, outsiders might find the modernist and post-modernist built environment of present-day Dalian monotonous to a certain extent.

In the Dalian and Chinese context, an open space could describe a wide array of areas ranging from open spaces between buildings, tree-planted reserves next to roads and undeveloped steep slopes of hilly topography. On the other hand, parks are more specifically perceived as manicured gardens and paved areas that can vary in size for recreational purposes. For this reason, it was not unexpected that more than $75 \%$ of the interviewees in the case study claimed that they lived in close proximity to open spaces. Slightly less than $62 \%$ indicated that they were close to parks (see Table 3). In terms of the two variables, there were no interviewees that were of the opinion

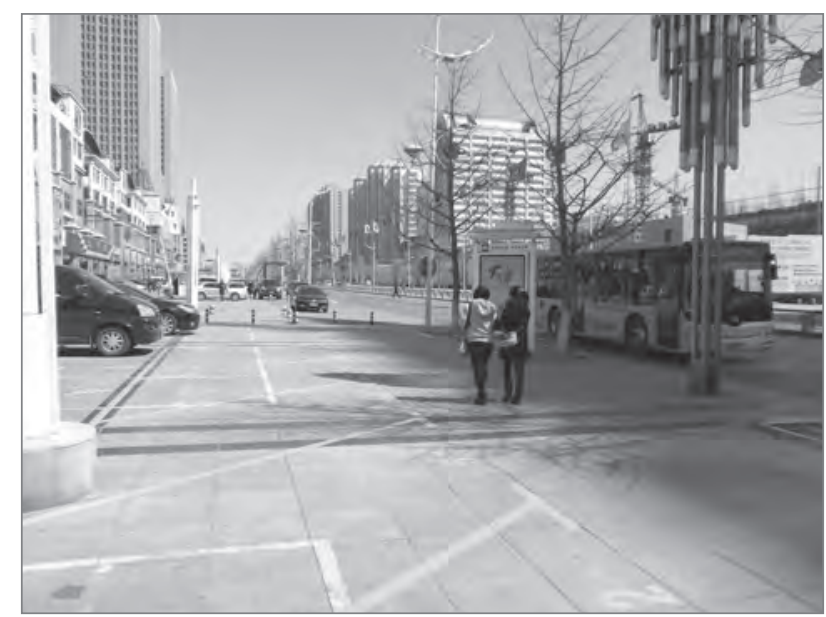

Figure 3: Development Zone Dalian, commercial and apartment development (photo: Nico Kotze). 
that open areas were remote and out of reach for them. These statistics could contribute to a perception that the city inhabitants' QOL meets their expectations.

With the large numbers of private cars, taxis and busses in the bustling streets and highways of the downtown area and the Dalian Development Zone during business hours, it seems that transport in the city should not be a problem. As opposed to cities like Beijing and Shanghai, the use of public transport in Dalian has remained fairly consistent, with only a $6 \%$ decline in its use over a 30 -year period, from $74 \%$ in 1975 to $68 \%$ in 2005. However, owing to car-friendly policies, a boom in the automobile industry and a rising per-capita income during the late 20th century, the use of public transport dropped to only 40\% in 2011 (Mu et al., 2012). Although this study did not investigate the use of public transport, almost $65 \%$ of the interviewees indicated that they were in close proximity to busses and bus routes, whereas only $5.9 \%$ indicated that they were far from such services.

There is no railway or underground railway system in operation within Dalian and only one rapid railway-line connects the Free Trade Area and the Development Zone with downtown Dalian. This must be the reason why the majority of the interviewees had negative attitudes about these services and why $60.7 \%$ indicated that railway facilities were far away from them (see Table 3). According to Rui Mu et al.(2012), the biggest problem with public transport in Dalian at present is that the city is fragmented, which weakens service provision.

In the context of schools, this paper only investigates the interviewees' responses to the location of all types of schools (pre-primary, primary and secondary schools). Just over $48 \%$ of the interviewees indicated that they were in close proximity to schools (see Table 3). In terms of the individual types of schools, it appears that the interviewees were not that concerned with the location of and their proximity to pre-primary and primary schools, but were more so in the case of high schools. The responses concerning the locations of medical facilities also reflected relatively low percentages, with just over $46 \%$ of the interviewees claiming that they were in close proximity to medical facilities. In a health survey in Zhejiang Province, China, Biao Zhou et al. (2011) found that the urban population had perceptions of a better QOL than their rural counterparts.

In terms of the multi-family high-rise developments in Dalian, it is apparent that a large number have commercial space on the street level. These areas are occupied by a wide range of business-related activities, ranging from small general shops to a variety of restaurant types. The relatively low percentage $(33.7 \%)$ of interviewees who indicated that they were in close proximity to such services seems strange. However, since the large departmental stores are fewer in number, it could be that the interviewees were referring to them when they responded to this question. Given the large number of restaurants within the city, the $66.9 \%$ of interviewees indicating that they were in close proximity to them seems accurate (see Table 3).

Considering the variables discussed in this section, it appears that the inhabitants of Dalian are not all that dissatisfied with the availability of open spaces, services, facilities and conveniences that make life easier. As such, the QOL in Dalian should be considered to be acceptable to its residents.

\section{Conclusion}

Although this was not a study on QOL per se, a variety of variables were used to test the interviewees' perceptions of life and living conditions in Dalian. In terms of their socioeconomic attributes, the interviewees were young, lived in small households and had good tertiary qualifications. The majority of the household heads were permanently employed, and most of the households had multiple sources of incomes. However, it should be kept in mind that these findings could have been influenced by the methodology employed in collecting the data.

Parks and open spaces are perceived in QOL studies as contributing positively towards a better life in urban areas. The interviewees in this case study recognised this variable as being accessible to them. Although the use of private transport in Dalian has rapidly increased since the end of the $20^{\text {th }}$ century, on account of policies leaning towards the use of private vehicles, the majority of the people in the case study were of the opinion that transport by bus was still within easy reach. Other services such as those delivered by medical facilities, schools and restaurants were also perceived as being accessible. There was only one variable - namely, the location of shops - that yielded unexpected results. All of the variables tested in this case study appear to have contributed towards positive living conditions and a better QOL in Dalian.

However, as stated earlier, satisfactory home ownership and residential areas are perceived by scholars as being the more important requirements for attaining happiness, a sense of well-being and a good QOL overall. In the Dalian case study, it was found that the majority of the interviewees were the owners of their housing units. In contrast to trends in the rest of the world, the average size of apartments in China appears to be increasing. They are also becoming more luxurious in order to keep up with the demands of the Chinese population. Nevertheless, the satisfaction levels with respect to housing units in this case study were apparently not very high in the 
context of the kitchen and the bathroom, as well as the overall quality of the apartment as a whole. What was very obvious in this case study was that the majority of the interviewees were uncertain about these three variables. This could be the result of either poor workmanship in the housing development schemes or a constant demand for better housing from the population of Dalian.

Juyong Zhang

Dalian Nationalities University, Economy and Management College, Dalian, China

\section{Nico Kotze}

University of Johannesburg, Department of Geography,

Environmental Management and Energy Studies, Johannesburg,

South Africa

E-mail:nicok@uj.ac.za

\section{Minghui Yu}

Dalian Nationalities University, Economy and Management College, Dalian, China

\section{References}

Baiden, P., Arku, G., Luginaah, I. \& Asiedu, A. B. (2011) An assessment of residents' housing satisfaction and coping in Accra, Ghana. Journal of Public Health, 19(1), pp. 29-37. DOI: 10.1007/s10389-010-0348-4

Bonaiuto, M., Fornara, F. \& Bonnes, M. (2003) Indexes of perceived residential environment quality and neighbourhood attachment in an urban environment: A confirmation study on the city of Rome. Landscape and Urban Planning, 65(1-2), pp. 41-52. DOI: 10.1016/S01692046(02)00236-0

China Tour Online (2012) Dalian History. Available at: http:// www. chinatouronline.com (accessed 23 Mar. 2012).

Diaz-Serrano, L. (2009) Disentangling the housing satisfaction puzzle: Does homeownership really matter? Journal of Economic Psychology, 30(5), pp. 745-755. DOI: 10.1016/j.joep.2009.06.006

Dunn, J. R. (2002) Housing and inequality in health: A study of socioeconomic dimensions of housing and self-reported health from a survey of Vancouver. Journal of Epidemical Community Health, 56(9), pp. 671-681. DOI: 10.1136/jech.56.9.671

Easterlin, R. A. (2006) Life cycle happiness and its sources: Intersections of psychology, economics and demography. Journal of Economic Psychology, 27(4), pp. 463-482. DOI: 10.1016/j.joep.2006.05.002

Gabriel, Z. \& Bowling, A. (2004) Quality of life from the perspectives of older people. Ageing and Society, 24(5), pp. 675-677. DOI: 10.1017/ S0144686X03001582

Galster, C. C. \& Hesser, G. W. (1981) Residential satisfaction: Compositional and contextual correlates. Environment and Behavior, 13(6) pp. 735-758. DOI: 10.1177/0013916581136006

Geng, Y., Zhu, Q., Doberstein, B. \& Fujita, T. (2009) Implementing China's circular economy concept at the regional level: A review of progress in Dalian, China. Waste Management, 29(2), pp. 996-1002. DOI: 10.1016/ j.wasman.2008.06.036

Higgins, P. \& Campanera, J. M. (2011) (Sustainable) quality of life in English city locations. Cities, 28(4), pp. 290-299. DOI: 10.1016/ j.cities.2011.02.005
Kährik, A., Leetmaa, K. \& Tammaru, T. (2012) Residential decision-making and satisfaction among new suburbanites in the Tallinn urban region, Estonia. Cities, 29(1), pp. 49-58. DOI: 10.1016/j.cities.2011.07.005

Lee, S., Ellis, C. D., Kweon, B. \& Hong, S. (2008) Relationship between landscape structure and neighbourhood satisfaction in urban areas. Landscape and Urban Planning, 85(1), pp. 60-70. DOI: 10.1016/j.landurbplan.2007.09.013

McCulloch, A. (2012) Housing density as a predictor of neighbourhood satisfaction among families with young children in urban England. Population, Space and Place, 18(1), pp. 85-99. DOI: 10.1002/psp.650

Møller, V. (2001) Monitoring quality of life in cities: The Durban case. Development Southern Africa, 18(2), pp. 217-238.

Moolla, R., Kotze, N. \& Block, L. (2011) Zadovoljstvo s stanovanji v naselju Braamfischerville v Sowetu in kakovost življenja v njih: študija primera iz Južnoafriške republike [Housing satisfaction and quality of life in RDP houses in Braamfischerville, Soweto: A South African case study]. Urbani izziv, 22(1), pp. 60-65 [138-143]. DOI: 10.5379/urbaniizziv-en-2011-22-01-005

Mu, R., De Jong, M., Yu, B. \& Yang, Z. (2012) The future of the modal split in China's greenest city: Assessing options for integrating Dalian's fragmented public transport system. Policy and Society, 31(1), pp. 5171. DOI: 10.1016/j.polsoc.2012.01.002

Naudé, W., Rossouw, S. \& Krugell, W. (2009) The non-monetary quality of life in city life in South Africa. Habitat International, 33(4), pp. 319326. DOI: 10.1016/j.habitatint.2008.08.004

Ornstein, S. W., Villa, S. B. \& Ono, R. (2011) Residential high-rise buildings in São Paulo: Aspects related to adequacy to the occupant's needs. Journal of Housing and the Built Environment, 26(1), pp. 73-84. DOI: 10.1007/s10901-010-9200-y

Pacione, M. (1990) Urban liveability. Urban Geography, 11(1), pp. 1-30 DOI: 10.2747/0272-3638.11.1.1

Pacione, M. (2003) Urban environmental quality and human wellbeing - a social geographical perspective. Landscape and Urban Planning, 65(1-2), pp. 19-30. DOI: 10.1016/S0169-2046(02)00234-7

Perrings, C. (1998) Income, consumption and human development: Environmental linkages. In: United Nations Development Program (ed.) Consumption for human development. Human development report. Background paper, pp. 151-212. New York, Human Development Report Office.

Shin, S. (2004) Economic globalization and the environment in China: A comparative case study of Shenyang and Dalian. Journal of Environment and Development, 13(3), pp. 263-294. DOI: 10.1177/1070496504268352

Smith, S. J., Easterlow, D., Munro, M. \& Turner, K. T. (2003) Housing as health capital: How health trajectories and housing paths are linked. Journal of Social Issues, 59(3), pp. 501-525. DOI: 10.1111/15404560.00075

Temelová, J. \& Dvořákoná, N. (2012) Residential satisfaction of the elderly in city centre: The case of revitalising neighbourhoods in Prague Cities, 29(5), 310-317. DOI: 10.1016/j.cities.2011.11.015

Travel China Guide (2012) Dalian Travel Guide. Available at: http://www. travelchinaguide.com (accessed 23 Mar. 2012).

Tress, B. \& Tress, G. (2001) Capitalising on multiplicity: A transdisciplinary systems approach to landscape research. Landscape and Urban Planning, 57(3-4), pp. 142-157. DOI: 10.1016/S0169-2046(01)00200-6

Ülengin, B., Ülengin, F. \& Güvenç, Ü. (2001) A multidimensional approach to urban quality of life: The case of Istanbul. European Journal of Operational Research, 130(2), pp. 361-374. DOI: 10.1016/S03772217(00)00047-3 
Wang, B., Li, X., Stanton, B. \& Fang, X. (2010) The influence of social stigma and discriminatory experience on psychological distress and quality of life among rural-to-urban migrants in China. Social Science and Medicine, 71(1), pp. 84-92. DOI: 10.1016/j.socscimed.2010.03.021

Westaway, M. S. (2006) A longitudinal investigation of satisfaction with personal and environmental quality of life in an informal South African housing settlement, Doornkop, Soweto. Habitat International, 30(1), pp. 175-189. DOI: 10.1016/j.habitatint.2004.09.003

Yau, Y. (2011) Ali celovita sanacija vpliva na spremembo cen stanovanj? Študija primera v predelu Mongkok v Hongkongu [Does comprehensive redevelopment change the housing price gradient? A case study in Mongkok, Hong Kong]. Urbani izziv, 22(2), pp. 25-33 [98-106]. DOI: 10.5379/urbani-izziv-en-2011-22-02-003

Zhou, B., Chen, K., Wang, J., Wang, H., Zhang, S. \& Zheng, W. (2011) Quality of life and related factors in the older rural and urban Chinese populations in Zhejiang Province. Journal of Applied Gerontology. 30(2), pp. 199-225. DOI: 10.1177/0733464810361346 